\title{
Heat Transfer Characteristics of a Horizontal Wire in Pools of Liquid and Supercritical Hydrogen
}

\section{AUTHOR(S):}

Tatsumoto, Hideki; Shirai, Yasuyuki; Shiotsu, Masahiro; Naruo, Yoshihiro; Kobayashi, Hiroaki; Inatani, Yoshifumi

\section{CITATION:}

Tatsumoto, Hideki ... [et al]. Heat Transfer Characteristics of a Horizontal Wire in Pools of Liquid and Supercritical Hydrogen. Journal of Superconductivity and Novel Magnetism 2015, 28(3): 1185-1188

\section{ISSUE DATE:}

2015-03

URL:

http://hdl.handle.net/2433/228369

\section{RIGHT:}

The final publication is available at Springer via https://doi.org/10.1007/s10948-014-2706-x; The full-text file will be made open to the public on 1 March 2016 in accordance with publisher's 'Terms and Conditions for Self-Archiving'; This is not the published version. Please cite only the published version.; この論文は出版社版でありません。引用の際には 出版社版をご確認ご利用ください。 
Heat transfer characteristics of a horizontal wire in a pool of liquid and supercritical hydrogen $\underline{\text { H. Tatsumoto }}{ }^{1}$, Y. Shirai ${ }^{2}$, M. Shiotsu ${ }^{2}$, Y. Naruo ${ }^{3}$, H. Kobayashi ${ }^{3}$.Y. Inatani. ${ }^{3}$

${ }^{1}$ Japan Atomic Energy Agency, J-PARC center, 319-1195, Tokai, Japan

${ }^{2}$ KyotoUniversity, Dept. of Energy Science \& Technology, 606-8501, Kyoto, Japan

3Japan Aerospace Exploration Agency, Institute of Space and Astronautical Science, 229-8510, Sagamihara, Japan

e-mail:tatumoto@post.j-parc.jp, telephone: +81-29-284-3742, FAX: +81-29-282-6496

\begin{abstract}
.
Heat transfer from a horizontal wire immersed in liquid and supercritical hydrogen was measured with a quasi-steady increase of a heat generation rate for wide range of bath temperatures and pressures. The nucleate boiling heat transfer coefficient is higher for higher pressure. The CHF is highest in the vicinity of $0.4 \mathrm{MPa}$ and is expressed by Kutateladze's equation. The CHFs become higher for higher subcooling. The heat transfer under supercritical pressure is the same as natural convection heat transfer in liquid hydrogen, but it detoriorates for the heated surface temperautre higher than pseudo-critical temperature. The heat transfer correlation was derived based on the experimental data.
\end{abstract}

Keywards: Heat transfer, pool boiling, Liquid hydrogen, Suercritical pressure

\title{
Introduction
}

Liquid hydrogen is expected as a coolant for high-Tc superconducting devices because of its excellent cooling properties. Several workers [1-3] have mainly investigated the pool boiling heat transfer of saturated liquid hydrogen at atmospheric pressure. However, there has been a lack of systematic experimental data of heat transfer characteristics in a pool of liquid hydrogen for wide ranges of pressure and supercritical hydrogen.

Tatsumoto et al. [4] have developed an experimental system for liquid hydrogen to systematically investigate not only pool boiling but also forced convection heat transfer. Shirai et al. [5] measured critical heat fluxes (CHF) from a flat plate in a pool of saturated and subcooled liquid hydrogen for the pressure of $0.1 \mathrm{MPa}$ to near the critical pressure. They reported that the CHFs are smaller than the values by Kutateladze's correlation [6] for higher pressures because the CHFs would be determined not by the heat flux due to hydrodynamic instability but by upper limit of the surface temperature.

The purpose of this study is to clarify pool boiling heat transfer from a wire in pool of saturated and subcooled liquid hydrogen compared with that from the flat plate [6]. Furthermore, the heat transfer characteristics in pool of cryogenic hydrogen at supercritical pressure is clarified and the heat transfer corelation is derived based on the experimental data.

\section{Experimental Apparatus and Method}

Details of the experimental system and the measurement procedure have already been described in a previous paper [5]. The cryostat whose design pressures are 2.1 MPa has an inner diameter of $406 \mathrm{~mm}$ and a height of $1495 \mathrm{~mm}$. The maximum inventory of liquid hydrogen is $50 \mathrm{~L}$. Liquid hydrogen in the cryostat is pressurized to a desired value by pure hydrogen gas from hydrogen gas bottles. The bath temperature, $T_{b}$, is controlled by a sheathed heater and is measured by Cernox sensors with the accuracy of $10 \mathrm{mK}$. Powers leads are 
installed to introduce the heating current up to 400 A to the test heater. For explosion protection, the power cables are covered with nitrogen gas blanket pipes.

A wire test heater made of Pt-Co with the length of $101.8 \mathrm{~mm}$ and the diameter of 1.2 $\mathrm{mm}$ is horizontally immersed in the cryostat. The copper current leads were brazed at both ends of the test heater and the voltage taps $(70 \mu \mathrm{m})$ were set at $8 \mathrm{~mm}$ from both ends.

The electric resistance of the heater was measured using a double-bridge circuit. The output voltage of the bridge circuit, the voltage drop across the potential taps of the heater, and the voltage drop across a standard resistance were measured at an interval of $30 \mathrm{~ms}$. The average temperature, $T_{a v}$, was estimated using the electrical resistance, which had been calibrated previously. The surface heat flux, $q$, was given as the difference between the heat generation rate, $Q$, and the time rate of change of energy storage. The average temperature on the heated surface, $T_{w}$, was calculated by solving the conduction equation in the radial direction of the cylinder using $T_{a v}$ and $Q$.

Pool boiling heat transfer was measured with a quasi-steady increase of the heat generation rate, $Q_{0} \mathrm{e}^{\mathrm{t} / \tau}$, with $\tau=10.0 \mathrm{~s}$ at the pressures of $0.4,0.7$ and $1.1 \mathrm{MPa}$. The bath temperatures were set from $20.5 \mathrm{~K}$ to its saturated temperature. Furtheremore, heat transfer characteristic was measured in a pool of cryogenic hydrogen at the pressure of $1.5 \mathrm{MPa}$ and at the bath temperatures of $21 \mathrm{~K}$ to $32 \mathrm{~K}$.

\section{Results and Discussion}

\section{Heat transfer characteristics in a pool of liquid hydrogen.}

Fig.1 shows heat transfer characteristics in pool of saturated liquid hydrogen for the pressure of 0.1 to $1.1 \mathrm{MPa}$ where transverse axis indicates the heater surface superheat, $\Delta T_{\text {sat }}$ $\left(=T_{w}-T_{s a t}\right)$. Temperature setback is small at the incipient of nucleate boiling. With slight increase in $\Delta T_{\text {sat }}$, the heat flux, $q$, drastically increases up to critical heat flux (CHF), $q_{c r}$, where an abrupt heated surface temperature rise appears due to transition to film boiling regime and does not extend beyond $100 \mathrm{~K}$ unlike non-cryogenic fluid. The nucleate boiling heat transfer coefficient is higher for higher pressure. The CHF increase with increase in pressure up to $0.4 \mathrm{MPa}$ but it becomes smaller for higher pressure. The film boiling heat transfer coefficient becomes higher for higher pressure.

Fig.2 shows a typical heat transfer characteristics in pool of subcooled liquid hydrogen at the pressure of $0.7 \mathrm{MPa}$, where $T_{\text {sat }}$ is $29.03 \mathrm{~K}$, for subcoolings of $0 \mathrm{~K}, 5.03 \mathrm{~K}$ and $8.23 \mathrm{~K}$. Transverse axis indicates the excess heated surface temperature beyond bath temperature, $\Delta T_{L}$ $\left(=T_{w^{-}} T_{b}\right)$. The natural convection heat transfer can be expressed by McAdams equation [7].

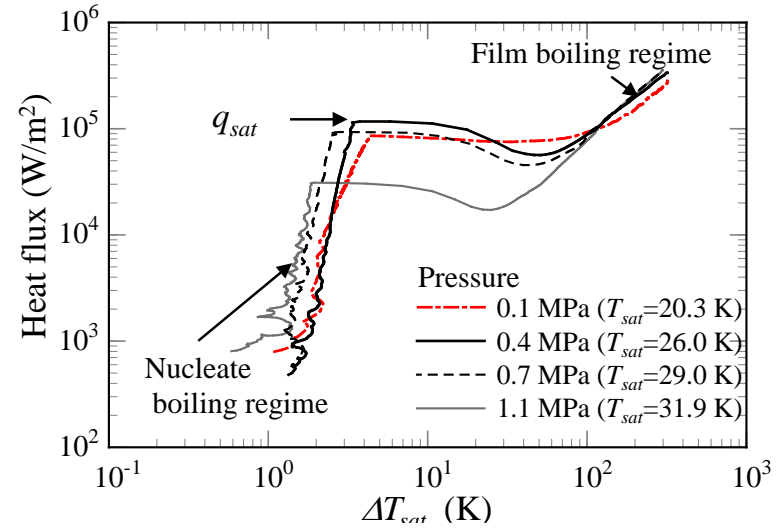

Fig.1 Heat tranfer characteristics for saturated liquid hydrogen.

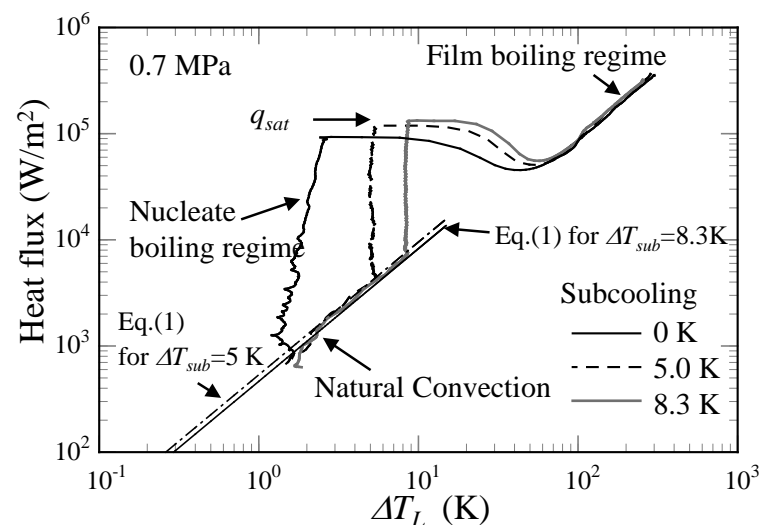

Fig.2 Heat tranfer characteristics for subcooled liquid hydrogen at $0.7 \mathrm{MPa}$. 
$N u=0.53(G r P r)^{1 / 4}$

where $\mathrm{Nu}$ is Nusselt number, $\mathrm{Gr}$ is Grashof number and $\mathrm{Pr}$ is Prandtl number.

The temperature setback is small at incipient of nucleate boiling. The CHF becomes higher for higher subcooling. Subcooling has relatively little effect on the film boiling heat transfer.

\section{Critical heat flux}

Fig.3 shows the effect of pressure on CHF under saturated condition. The data of CHF from a horizontal flat plate measured by Shirai et al. [5] are also plotted in the figure. The CHF is highest in the vicinity of 0.4 MPa like that for the flat plate. The pool boiling CHF, $q_{c r, s a t}$, in saturated condition is expressed by Kutateladze's equation as follows [6].

$q_{c r, s a t}=0.16 h_{f g} \rho_{v}\left\{g \sigma\left(\rho_{l}-\rho_{v}\right) / \rho_{v}^{2}\right\}$

where $h_{f g}$ is the latent heat, $\rho$ is the density, $g$ is the gravity, and $\sigma$ is the surface tension. The subscripts of $l$ and $v$ indicate liquid and vapor.

The predicted values by Eq.(2) are also shown in the figure. The experimental data agree well with the predicted values by Eq.(2) for the pressures lower than $0.4 \mathrm{MPa}$. However, the data are lower for the higher pressures. Fig.4 shows the effect of the pressure on the heated surface temperatures at CHFs. With increase in pressure, the heated surface temperatures increase up to critical temperature and are kept constant for the pressure higher than $0.7 \mathrm{MPa}$. Therefore, it is assumed that the transition to film boiling would occur at the heat flux lower than that caused by hydrodynamic instability and be dominated by the heated surface temperature [5].

Fig.5 shows the effect of subcooling on $\mathrm{CHF}$ at the pressures of $0.4,0.7$ and $1.1 \mathrm{MPa}$. It seems that, with increase in subcooling from $\Delta T_{\text {sub }}=0$, the CHFs increase in proportional to subcooling. The CHF for subcooled pool boiling, $q_{c r, s u b}$, is predicted by Kutateladze's equation as follows [8].

$q_{c r, s u b} / q_{c r, s a t}=1+0.065\left(\rho_{v} / \rho_{l}\right)^{0.8}\left(C_{p l} \Delta T_{s u b} / h_{f g}\right)$

where $C_{p l}$ is the specific heat.

Fig.6 shows comparison of the experimental data with the correlations. The experimental data increase in proportional to the non-dimensional subcooling of $S c=C_{p l} \Delta T_{s u b} / h_{f g}$. It is found

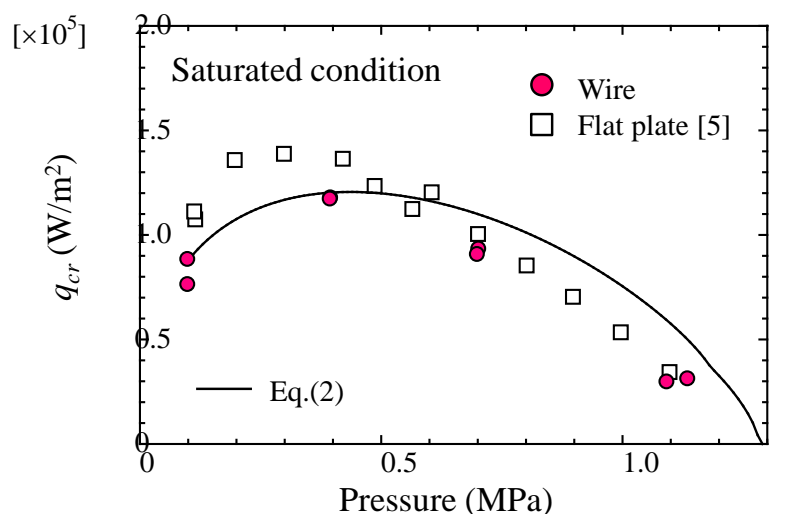

Fig.3 Effect of pressure on CHF in saturated condition.

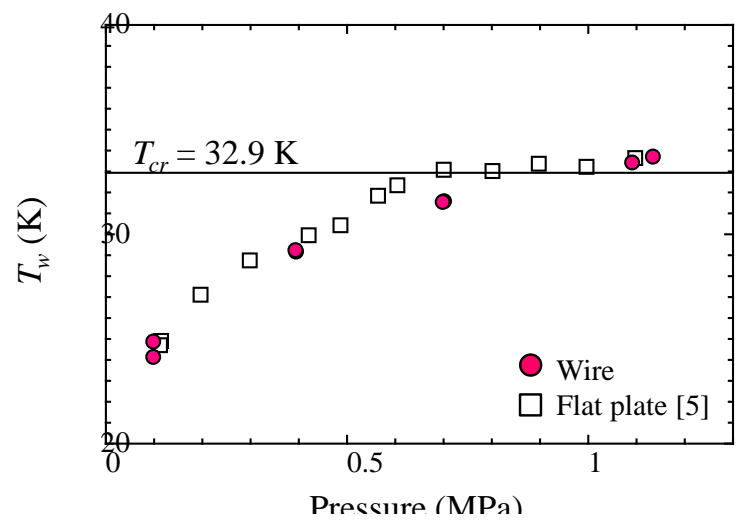

Fig.4 Heated surface temperature at $\mathrm{CHF}$ 


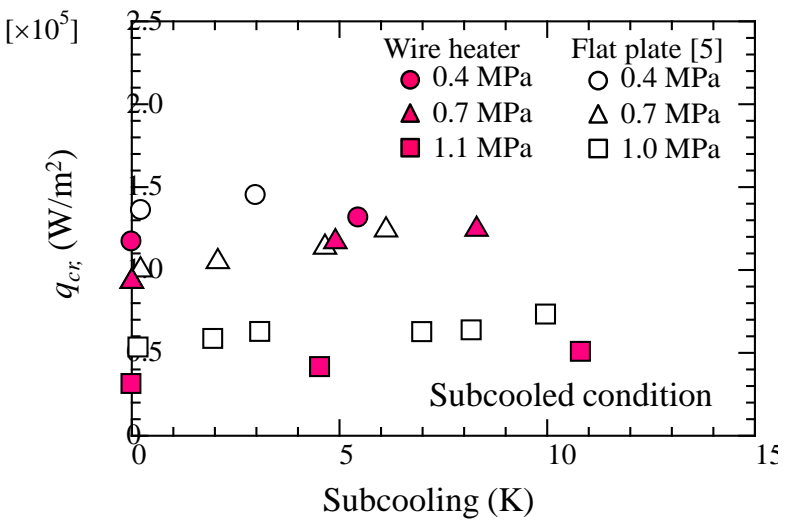

Fig.5 CHF in subcooled liquid hydrogen for pressures from 0.4 to $1.1 \mathrm{MPa}$

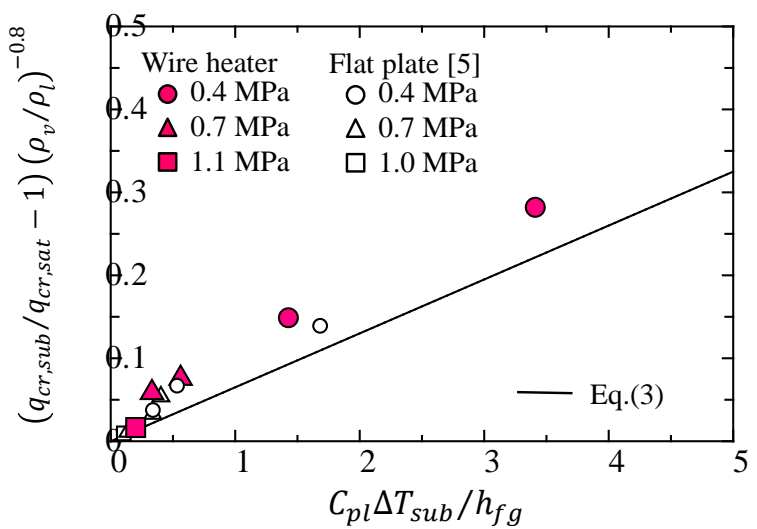

Fig.6 Comparison of CHF in subcooled liquid with Eq.(3).

that the effect of subcooling on the CHF for not only the wire but also the flat plate can be well expressed by Eq.(4).

\section{Heat transfer characteristics in a pool of cryogenic hydrogen at supercritical pressure Conclusion}

Fig.7 shows a typical heat transfer characteristics at the supercritical pressure of 1.5 MPa where the pseudo critical temperature, $T_{c r}$ ', is $34 \mathrm{~K}$. The bath temperatures are $21 \mathrm{~K}$ and $32 \mathrm{~K}$, respectively. The heat transfer curve for subcooled liquid hydrogen at the temperature of $20.9 \mathrm{~K}$ and the pressure of $1.1 \mathrm{MPa}$, which is slightly lower than the critical pressure, is also plotted in Fig.7 (a). For $T_{w}<T_{c r}$, the heat transfer characteristic is similar to that for subcooled liquid hydrogen and can be also expressed by Eq.(1). Above $T_{c r}$ ', the heat transfer deteriorates continuously and is lower than the predicted value by Eq.(1), while it is enhanced due to nucleate boiling for liquid hydrogen. However, it can be seen that the heat transfer is enhanced around $\Delta T_{L}=110 \mathrm{~K}$. It seems that the heat transfer coefficient above $T_{c r}$ ' is similar to that for film boiling heat transfer, although the phenomena is different.

We have derived a correlation of forced convection heat transfer of supercritical hydrogen by modifying Dittus-Boelter equation to express the degradation of heat transfer due to the growth of thermal boundary layer [9]. In this study, a heat transfer correlation in pool of cryogenic hydrogen at supercritical pressure is derived by modifying Eq.(1) and introducing the terms of $\left(\rho_{w} / \rho_{b}\right)^{\mathrm{n}}\left(\mu_{b} / \mu_{w}\right)^{\mathrm{m}}$ based on the experimental data.

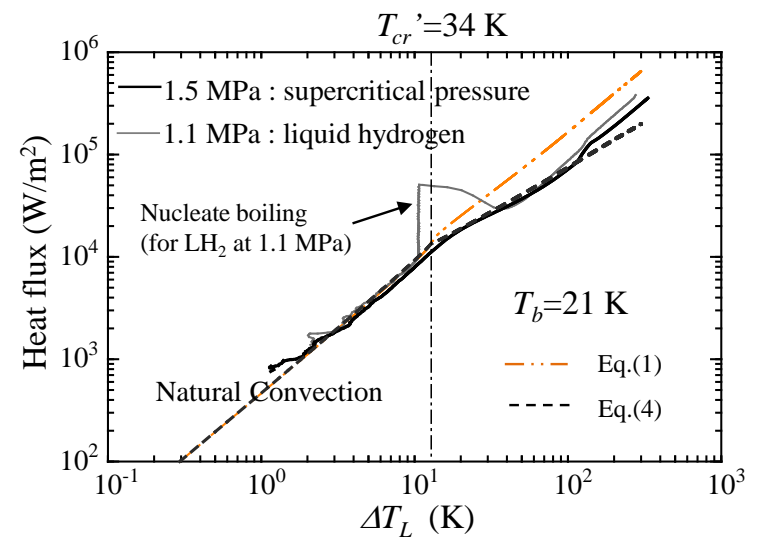

(a) $T_{b}=21 \mathrm{~K}$

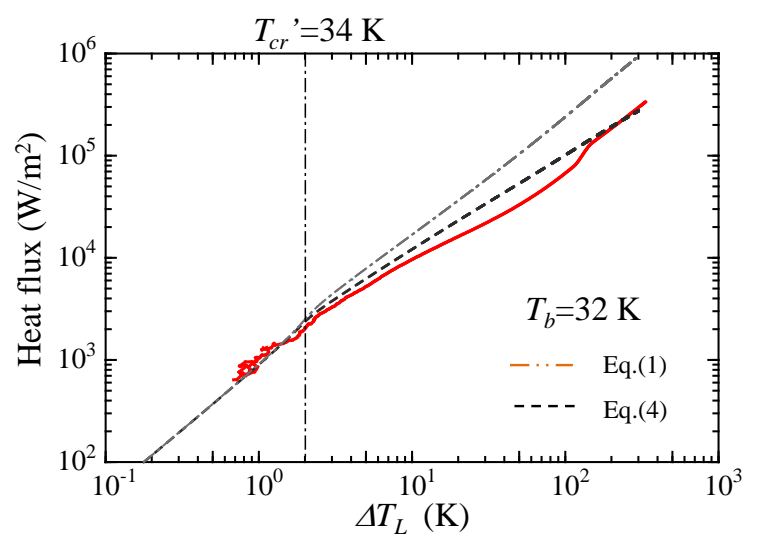

(b) $T_{b}=32 \mathrm{~K}$

Fig.7 Heat transfer characteristics in a pool of cryogenic hydrogen at supercritical pressure of 1.5 MPa. 


$$
N u=0.53(G r \overline{P r})^{1 / 4}\left(\rho_{w} / \rho_{b}\right)^{0.3}\left(\mu_{b} / \mu_{w}\right)^{0.15}
$$

The predicted values by Eq.(6) are plotted in Fig.7. The experimental data can be described by our correlation within $40 \%$ for $\Delta T_{L}$ lower than $110 \mathrm{~K}$. The deviation becomes smaller for lower $T_{b}$ and it is within $15 \%$ for $T_{b}=21 \mathrm{~K}$.

\section{Conclusions}

Heat transfer from the wire in pool of liquid hydrogen MPa and supercritical hydrogen at the pressure of $1.5 \mathrm{MPa}$ was measured for various bath temperatures. Experimental results led to the following conclusion.

Non-boiling heat transfer is expressed by McAdams' equation. The nucleate boiling heat transfer coefficient is higher for higher pressure. The CHF is highest in the vicinity of 0.4 MPa. The CHFs are lower than the predicted values by Kutateladze's equation for higher pressures. This is because the transition to film boiling would be dominated by not the heat flux due to hydrodynamic instability but $T_{w}$. The CHFs become higher for higher subcooling.

The heat transfer of supercritical hydrogen continuously deteriorates above $T_{c r}$. The heat transfer coefficient is seems to be similar to that for film boiling heat transfer. A heat transfer correlation for supercritical hydrogen is derived by modifying Eq.(1) and can be expressed the experimental data within $40 \%$.

\section{Acknowledgements}

This research was supported in part by JST, ALCA. The authors thank the technical staffs of JAXA for their technical assistance.

\section{References}

[1] Coeling, KJ., Merte Jr H.,J. :Incipient and nucleate boiling of liquid hydrogen. Eng. Indus. 91, 513-24 (1969)

[2] Steward, WG. Onset of nucleate and film boiling resulting from transient heat transfer to liquid hydrogen. Advances in Cryogenic Engineering. 35, 403-411, 1990.

[3] Class, CR., Dehaan, JR., Piccone, M., Cost, RB., Boiling heat transfer to liquid hydrogen from flat surface. Advances in Cryogenic Engineering. 5, 54-62 (1960)

[4] Tatsumoto, H., Shirai, Y., Shiotsu, M., Hata, K., Kobayashi, H., Naruo, Y., Inatani, Y.,. J.Phys:Conf. Seri. 234, 032056 (2010).

[5] Shirai, Y., Tatsumoto, H., Shiotsu, M., Hata, K., Kobayashi, H., Naruo, Y., Inatani, Y., Boiling heat transfer from a horizontal flat plate in a pool of liquid hydrogen. Cryogenics. 50, 410-416 (2010)

[6] Kutateladze, SS., On the transition to film boiling under natural convection. Kotloturbostroenie. 3, 10-12 (1948)

[7] McAdams,

[8] Kutateladze, SS., Schneiderman LL., Experimental study of the influence of the temperature of a liquid on a change in the rate of boiling. AEC-tr-3405, 85-100 (1953)

[9] Shiotsu, M., Shirai, Y., Tatsumoto, H., Hata, K., Kobayashi, H., Naruo, Y., Inatani, Y., Forced flow heat transfer of supercritical hydrogen for superconductor cooling. Advances in Cryogenic Engineering, **,** (2013) 